\title{
Input-Output Feedback Linearization Control for IPMSM using Maximum Torque Per Ampere Strategy
}

\author{
Risha $\mathrm{Na}^{\mathrm{a}, *}$, Xudong Wang \\ a Harbin University of Science \& Technology, No.52 Xufu Road, Nangang District, Harbin,150080, China \\ b Harbin University of Science \& Technology, No.52 Xufu Road, Nangang District,, Harbin,150080, China
}

\begin{abstract}
In this paper, a Input-Output Feedback Linearization technique is discussed for Interior type Permanent Magnet Synchronous Motor (IPMSM). And it is designed on the basis of Maximum Torque per Ampere (MTPA) control strategy. Furthermore, a simple experimental method of obtaining the MTPA trajectory, which based on maximization of the output DC voltage in generation mode versus stator current, is considered. Simulation model is carried out and the results show the effectiveness of the proposed method.
\end{abstract}

Keywords: Input-Output Feedback Linearization (IOFL), Maximum Torque per Ampere (MTPA), Interior Permanent Magnet Synchronous Motor (IPMSM).

\section{Introduction}

In the last decades, IPMSM drives have been widely used in many applications such as traction and machine tool spindle drives [1], air conditioning compressors [2], [3], electrical vehicles [4], [5], and integrated starters/alternators [6], [7]. The reason why an IPMSM has become so popular is mainly due to its inherent advantages such as high efficiency, good dynamic, and small frame size compared to other motor with the same capacity [8].

Below the base speed, the maximum-torque-per-ampere (MTPA) control strategy is a very common choice. It allows to exploit both the magnet and the reluctance torque to maximize the torque-per-ampere ratio [9]. However, MTPA strategy is parameter dependent and its performance relies on the knowledge of motor parameters. It's very important for us to obtain the MTPA trajectory before we control it, and it's a quite complex task that can be accomplished according to different approaches. The first one is based on the simple machine model with constant parameters. Although it's very easy to be achieved, assuming that $\mathrm{L}_{d}$ and $\mathrm{L}_{q}$ not changed, the performance of the motor could not be very well. Comparatively, another one is based on using a detailed model of the machine, considering the inductance variation due to saturation and cross saturation. In this paper, an experimental method will be presented where the measurement of the output DC voltage as the motor working in generation mode is exploited to detect the MTPA trajectory at steady state, avoiding the use of adaptive observers or torque transducers.

In this paper, an input-output feedback linearization technique is used, compared with several nonlinear control methods, for MTPA control of IPMSM drive systems with test value of $\mathrm{L}_{d}$ and $\mathrm{L}_{q}$. The implementation of the proposed system by Matlab/Simulink is given. The experimental results show that the performance of the input-output linearization technique is better than that of the PI controller in transient response and steady error adjustable ability.

\section{IPMSM Model}

The model of the IPMSM drive in the rotor $d-q$ axis reference frame is given by:

$$
\left\{\begin{array}{l}
u_{d}=R_{s} i_{d}+\frac{d}{d t} \psi_{d}-\omega_{e} \psi_{q} \\
u_{q}=R_{s} i_{q}+\frac{d}{d t} \psi_{q}+\omega_{e} \psi_{d}
\end{array}\right.
$$

Where $\lambda_{\mathrm{d}}$ and $\lambda_{\mathrm{q}}$ are $\mathrm{d}-\mathrm{q}$ axis flux linkage; $\lambda_{\mathrm{f}}$ is permanent magnet flux linkage; $u_{\mathrm{d}}$ and $u_{\mathrm{d}}$ are $\mathrm{d}-\mathrm{q}$ axis stator voltages; $i_{\mathrm{d}}$ and $i_{\mathrm{q}} \mathrm{d}-\mathrm{q}$ axis stator currents; $R$ is stator 
resistance; $\omega_{\mathrm{r}}$ is the motor mechanical speed and $P$ is the pole pairs.

$$
\left\{\begin{array}{l}
\psi_{d}=L_{d} i_{d}+\psi_{f} \\
\psi_{q}=L_{q} i_{q}
\end{array}\right.
$$

The motor generated torque is

$$
T_{e}=p\left(\psi_{d} i_{q}-\psi_{q} i_{d}\right)
$$

In addition, the motor mechanical equations are given by

$$
\frac{J}{p} \cdot \frac{d \omega_{e}}{d t}=T_{e}-T_{L}
$$

Where $J$ is the rotor moment of inertia; $B$ is the friction coefficient and $T_{1}$ denotes the motor load torque.

\section{MTPA strategy}

Conventional vector control systems use only excitation torque, setting $i_{\mathrm{d}}$ commend to zero. Such control scheme is simple since the torque is controlled only by one variable, however it does not use the whole potentiality of the motor.

To utilize the reluctance torque of the motor, d-axis current should be controlled as well. The relationship between $i_{\mathrm{d}}$ and $i_{\mathrm{q}}$ for the archiving minimum of the stator current at the given torque can be obtained by differentiating (4) and equating result to zero. The result is:

$$
i_{d}=-\lambda_{f} / 2\left(L_{d}-L_{q}\right)+\sqrt{\lambda_{f}{ }^{2} / 4\left(L_{d}-L_{q}\right)^{2}+i_{q}{ }^{2}}
$$

Table.1 shows the parameters of the motor used in this paper. In fact, according to experimental measurement, as shown in Figs.1, due to saturation and cross coupling, both $L_{\mathrm{d}}$ and $L_{\mathrm{q}}$ are functions of current component $i_{\mathrm{q}}$, while they are almost unaffected by variations in $i_{\mathrm{d}}$.

Table 1. Machine Nominal Parameters

\begin{tabular}{|c|l|}
\hline Number of pole pairs & 8 \\
\hline Magnet flux linkage & $0.076 \mathrm{wb}$ \\
\hline$d$-axis inductance & $0.3 \mathrm{mH}$ \\
\hline$q$-axis inductance & $0.6 \mathrm{mH}$ \\
\hline Stator resistance & $31 \mathrm{~m} \Omega$ \\
\hline
\end{tabular}

Fig.2 shows, respectively, the simple model-based computed MTPA trajectory considering constant machine parameters (Table.1 and (6)), and the MTPA trajectory based on a detailed motor model considering the variation of parameters shown in Fig.1. Obviously, the use of constant-parameter models causes a reduction in the efficiency of the performance of the control. And the detailed model is able to provide a better description of the machine, but this method is required to obtain the accurate parameters value shown in Fig.1, which is a complex task that needs laboratory tests.

Actually, we always select an experimental approach to obtain the MTPA trajectory. Traditional experimental approaches need a torque transducer and an adjustable-load. Some alternative approaches that without torque measurement have been selected to determine a function relating $d-q$ axis current. Among them, the approach with output DC voltage measurement as the motor working in generation mode appears to be a viable solution. In fact, the motor output power (7) in generation mode could be approximately represented in (8). With no consideration of the variation of the resistance, the currents which generate the maximum values of the DC voltage on the resistance coincide with the currents that generate the maximum values of torque, at a fixed rotor speed. The drawback is that the proposed method cannot be applied at zero-speed condition.

$$
\begin{gathered}
P=T e \cdot n / 9550 \\
P=U^{2} / R
\end{gathered}
$$

Where $\mathrm{n}$ is the motor velocity, $U$ is the DC voltage on the resistance.

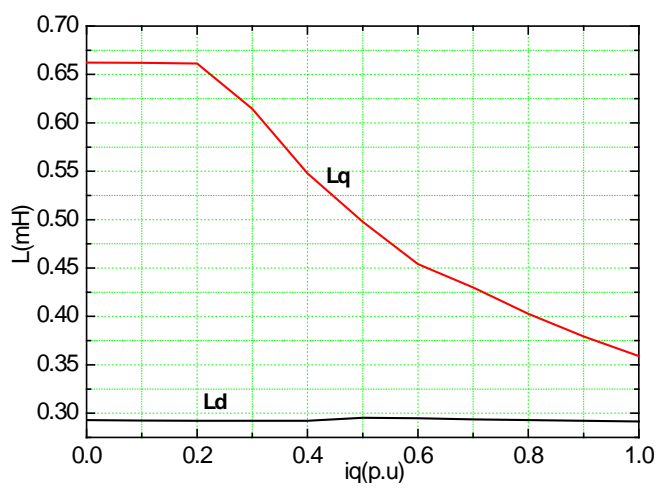

Fig. $1 L_{\mathrm{d}}$ and $L_{\mathrm{q}}$ versus $i_{\mathrm{q}}$

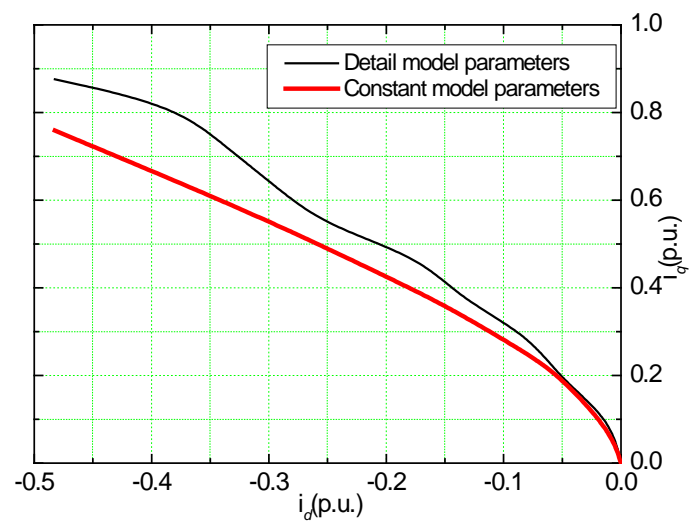


Fig. 2 Trajectories based on two different models for MTPA

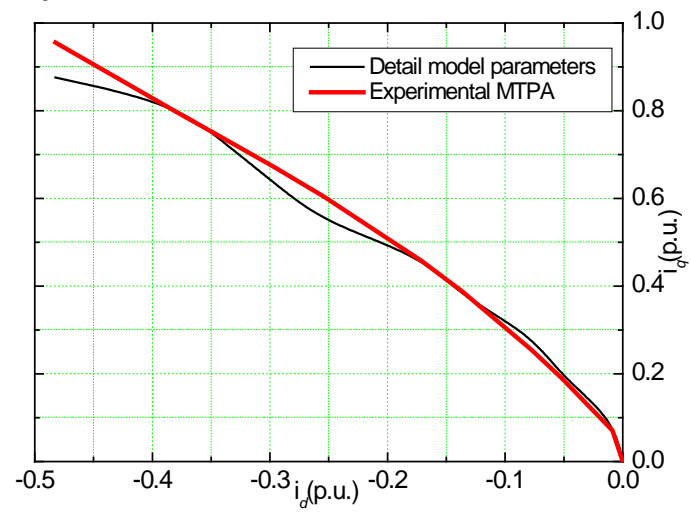

Fig. 3 Trajectories based on experimental method

To confirm the effectiveness of this approach, fig. 3 shows, respectively, the MTPA trajectory obtained by this approach and the trajectory obtained based on detail motor parameters, and the two trajectories are quite coincident.

\section{Input-Output Linearization of IPMSM}

IPMSM is a multivariable nonlinear system, including the coupling of the rotor electrical angular velocity a $\square$ nd the $\mathrm{d}-\mathrm{q}$ axis current in the $\mathrm{d}-\mathrm{q}$ synchronous frame. Traditional current vector control with the PI controller is based on the linear model, so the transient performance of the motor is not well. For this reason, several nonlinear controllers have been developed for the IPMSM to increase the drive systems performance. An adaptive self-tuning maximum torque/ampere vector controller has been proposed [12]. The results are satisfied, but the controller is very complicated. A genetic-algorithm-based fuzzy logic controller has been investigated [13]. However, the controller design requires a lot of knowledge and experience. An artificial-neural-network-based real-time adaptive controller has been proposed [14]. The system experimental performances are well, but the control algorithm is very complicated. Therefore, we choose feedback linearization technique to control IPMSM, and the system performance can be improved by achieving exact input-output decoupling and linearization via a nonlinear state feedback control.

The main aim of this technique is to obtain the reference space voltage vectors $u_{\mathrm{d}}$ and $u_{\mathrm{q}}$ which are capable of tracking the motor reference currents $i_{\mathrm{d}} *$ and $i_{\mathrm{q}} *$ perfectly. For this purpose, we choose $\lambda_{\mathrm{d}}, \lambda_{\mathrm{d}}$ and $\omega_{\mathrm{e}}$ as state vectors, and assume that $u_{\mathrm{d}}$ and $u_{\mathrm{q}}$ as control input vector. The state equation of IPMSM in the $d-q$ synchronous frame can be expressed as

$$
\left\{\begin{array}{l}
\dot{x}=f(x)+g_{1}(x) u_{1}+g_{2}(x) u_{2} \\
y_{1}=h_{1}(x) \\
y_{2}=h_{2}(x)
\end{array}\right.
$$

where

$$
\left\{\begin{array}{l}
x=\left[\begin{array}{lll}
x_{1} & x_{2} & x_{3}
\end{array}\right]^{T}=\left[\begin{array}{lll}
\lambda_{d} & \lambda_{q} & \omega_{e}
\end{array}\right]^{T} \\
u_{1}=u_{d} \\
u_{2}=u_{q}
\end{array}\right.
$$

And the system function is shown as follows

$$
f(x)=\left[\begin{array}{l}
-R i_{d}+L_{q} i_{q} \omega_{e} \\
-R i_{q}-L_{d} i_{d} \omega_{e}-\omega_{e} \varphi_{f} \\
\left\{\begin{array}{l}
1.5 P^{2}\left[\varphi_{f} i_{q}+\left(L_{d}-L_{q}\right) i_{d} i_{q}\right] \\
-P T_{l}-B \omega_{e}
\end{array}\right\} / J
\end{array}\right]
$$

and

$$
g(x)=\left[\begin{array}{ll}
g_{1} & g_{2}
\end{array}\right]=\left[\begin{array}{ll}
1 & 0 \\
0 & 1 \\
0 & 0
\end{array}\right]
$$

The output variables are introduced as follows.

$$
\left\{\begin{array}{l}
y_{1}=h_{1}(x)=\lambda_{d} \\
y_{2}=h_{2}(x)=\lambda_{q}
\end{array}\right.
$$

Then we can obtain

$$
\left\{\begin{array}{l}
\dot{y_{1}}=L_{f} h_{1}+L_{g_{1}} h_{1} u_{d}+L_{g 2} h_{1} u_{q} \\
\dot{y_{2}}=L_{f} h_{2}+L_{g_{1}} h_{2} u_{d}+L_{g 2} h_{2} u_{q}
\end{array}\right.
$$

with

$$
\left\{\begin{array}{l}
L_{g_{1}} h_{1}=g_{1} \partial h_{1} / \partial x=1 \\
L_{g_{2}} h_{1}=g_{2} \partial h_{1} / \partial x=0 \\
L_{g_{1}} h_{2}=g_{1} \partial h_{2} / \partial x=0 \\
L_{g 2} h_{2}=g_{2} \partial h_{2} / \partial x=1
\end{array}\right.
$$

Define a $2 \times 2$ matrix $\mathrm{D}(\mathrm{x})$ as follows, and we know the matrix defined in (16) is full order( $\mathrm{r}=2)$. 


$$
D(x)=\left[\begin{array}{cc}
L_{g_{1}} h_{1} & L_{g 2} h_{1} \\
L_{g_{1}} h_{2} & L_{g 2} h_{2}
\end{array}\right]=E
$$

Introducing the following new controlling variables:

$$
\left\{\begin{array}{l}
v_{1}=\dot{y}_{1} \\
v_{2}=\dot{y}_{2}
\end{array}\right.
$$

Thus from (14), (15) and (16) the system input dynamics is

$$
\left[\begin{array}{l}
u_{d} \\
u_{q}
\end{array}\right]=D^{-1}(x)\left[\begin{array}{l}
v_{1}-L_{f} h_{1} \\
v_{2}-L_{f} h_{2}
\end{array}\right]
$$

Introducing the new control variables $v 1, v 2$ and they are defined by

$$
\left\{\begin{array}{l}
v_{1}=\frac{d \varphi_{d}^{*}}{d t}-\alpha_{1} e_{d} \\
v_{2}=\frac{d \varphi_{q}{ }^{*}}{d t}-\alpha_{2} e_{q}
\end{array}\right.
$$

Where $\alpha_{1}$ and $\alpha_{2}$ are positive constant and $e_{d}=\varphi_{d}{ }^{*}-\varphi_{d}, e_{q}=\varphi_{q}{ }^{*}-\varphi_{q}$.Superscript “*”denotes the reference value.

Using (19) and (18), the system control efforts are shown as follows.

$$
\left\{\begin{array}{l}
v_{1}=\frac{d \varphi_{d}^{*}}{d t}-\alpha_{1} e_{d}=-R i_{d}+\omega_{e} \hat{L}_{q} i_{q}+u_{d} \\
v_{2}=\frac{d \varphi_{q}^{*}}{d t}-\alpha_{2} e_{q}=-R i_{q}-\omega_{e} \hat{L_{d}} i_{d}+\omega_{e} \varphi_{f}+u_{q}
\end{array}\right.
$$

The system error dynamics are

$$
\left\{\begin{array}{l}
\frac{d e_{d}}{d t}=-\alpha_{1} e_{d} \\
\frac{d e_{q}}{d t}=-\alpha_{2} e_{q}
\end{array}\right.
$$

Equation (21) shows that for positive $\alpha_{1}$ and $\alpha_{2}, e_{d}$ and $e_{q}$ exponentially converge to zero.

\section{Simulation Results}

The proposed control algorithm has been simulated for a three-phase IPMSM with parameters shown in table (1). The overall drive system control is implemented in a block diagram shown in Fig.4. The speed PI controller has been used to predict the required motor torque $T_{\mathrm{e}}$, and the $\mathrm{d}-\mathrm{q}$ axis current reference $i_{\mathrm{d}}{ }^{*}$ and $i_{\mathrm{q}}{ }^{*}$ are generated from $T_{\mathrm{e}}$ using a Look-Up-Table (LUT). The system controller gains are obtained by trial and error method in the proposed control approach. Simulated results are listed in Fig.5 to Fig.7, which show that the two axis currents are perfectly tracked.

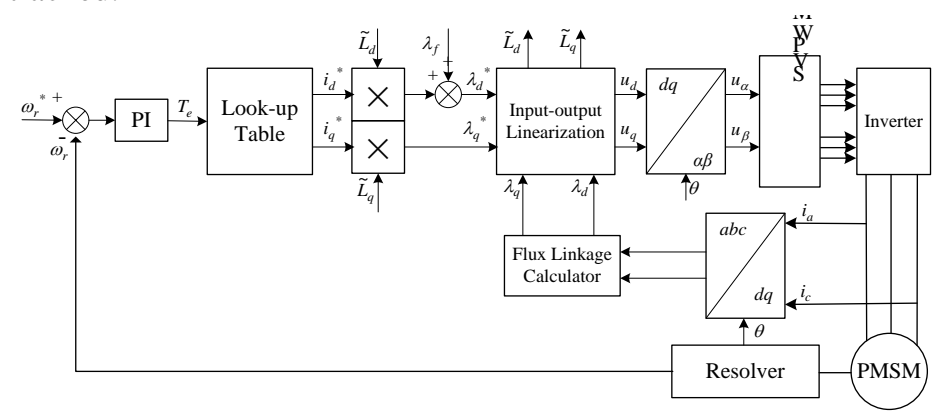

Fig. 4 Simulation diagram of PMSM IOFL control system

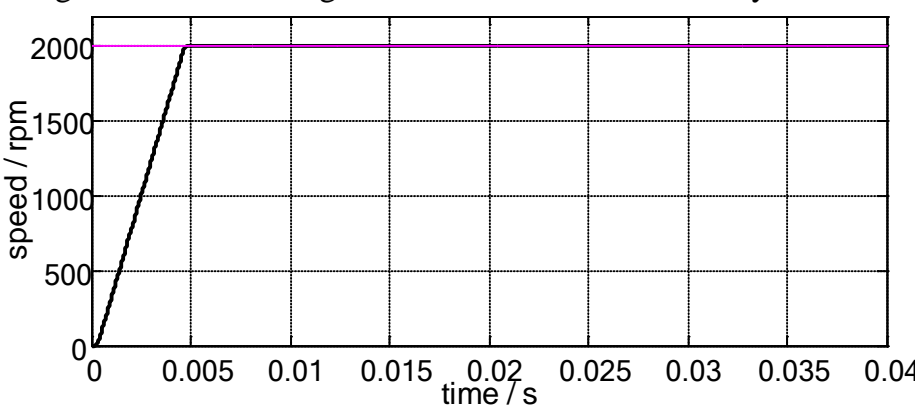

Fig. 5 Waveforms of speed at motor starting

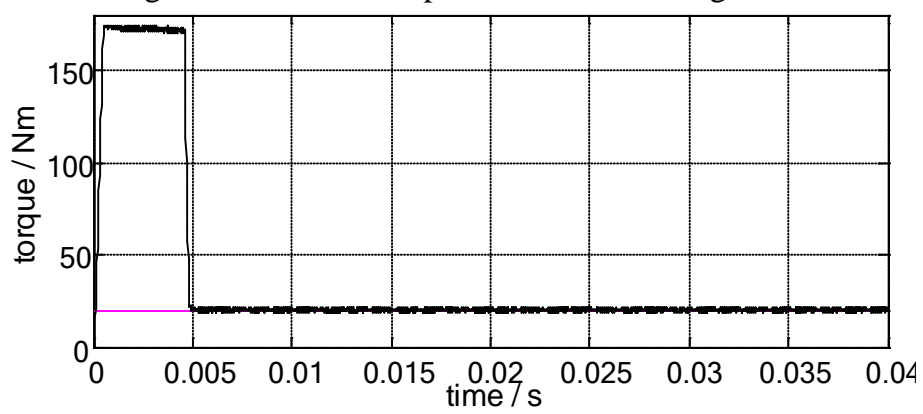

Fig. 6 Waveforms of torque at motor starting

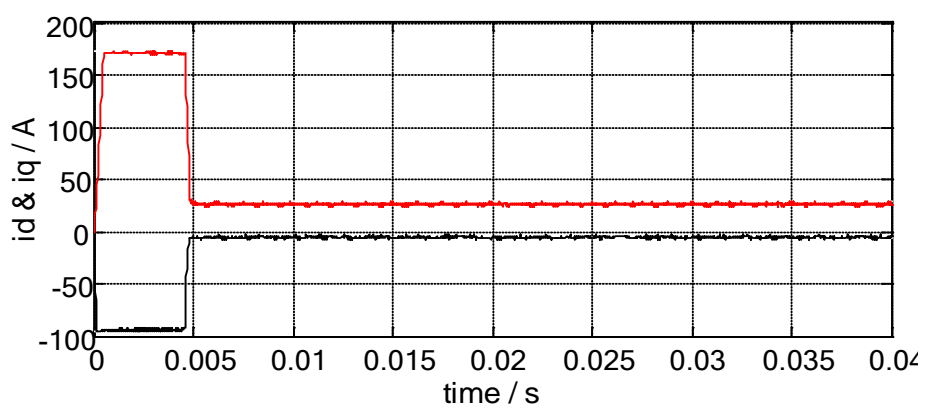

Fig. 7 Waveforms of currents at motor starting

\section{Conclusion}

In this paper, we propose an input-output feedback 
linearization control for a detail nonlinear model of IPMSM, which is employed for a robust MTPA control. Required motor torque is predicted by the motor speed PI controller. According to the proposed control approach, the desired speed and $\mathrm{d}-\mathrm{q}$ axis current references command are perfectly tracked. In addition, a simple experimental method has been proposed to obtain the trajectory of MPTA. Experimental results have confirmed the effectiveness of this method.

\section{References}

[1] Z. Q. Zhu, Y. S. Chen, and D. Howe, "Online optimal flux-weakening control of permanent-magnet brushless AC drives,” IEEE Trans. Ind. Appl., vol. 36, no. 6, pp. 1661-1668, Nov./Dec. 2000.

[2] I. Takahashi and H. Haga, "Inverter control method of IPM motor to improve power factor of diode rectifier," in Proc. IEEE PCC Conf., 02, pp. 142-147, 2002.

[3] H. Murakami,Y. Honda, H. Kiriyama, S. Morimoto, andY. Takeda, "The performance comparison of SPMSM, IPMSM, and SynRM in use as air-conditioning compressor," in Conf. Rec. IEEE-IAS Annu. Meeting, 1999, pp. 840-845.

[4] L. Chen, R. Davis, S. Stella, T. Tesch, and A. Fischer-Antze, "Improved control techniques for IPM motor drives on vehicle application," in Conf. Rec. IEEE-IAS Annu. Meeting, 2002, pp. 2051-2056.

[5] J. W. Park, D. H. Koo, J. M. Kim, and H. G. Kim, "High performance drive unit for 2-motor driven electric vehicle," in Conf. Rec. APEC Annu. Meeting, 1999, pp. 443-449.

[6] E. C. Lovelace, T. M. Jahns, and J. H. Lang, "Impact of saturation and inverter cost on interior PM synchronous machine drive optimization,” IEEE Trans. Ind. Appl., vol. 36, no. 3, pp. 723-729, May/Jun. 2000.

[7] J. Wai and T. M. Jahns, “A new control technique for achieving wide constant power speed operation with an interior PM alternator machine," in Conf. Rec. IEEE-IAS Annu. Meeting, 2001, pp. 807-814.

[8] M. Kadjoudy, M.E. Benbouzid and etc all, "A Robust hybrid current control for permanent-magnet synchronous motor drive ", IEEE Trans. On Energy conversion, Vol.19, No.1, pp. 109-115, march 2004.

[9] S. Morimoto, "Analysis, design and control of the IPM motor," in IEEE IAS Annu. Meeting Tutorial on Analysis, Design, and Control of Interior Permanent Magnet Synchronous Machines, 2004, pp. 8-1-8-35. chapter 8, IPM Vector Control and Flux Weakening.

[10] S. Ichikawa, M. Tomita, S. Doki, S. Okuma," Sensorless Control of Permanent-Magnet Synchronous Motors Using Online Parameter Identification Based on System Identification Theory”, IEEE Trans, On Ind. Elect., vol. 53, no. 2, pp. 363-372, April 2006.

[11] F.-J. Lin, "Robust speed controlled induction motor drive using EKF and RLS estimation,'” in Proc. Inst. Elect. Eng.--Elect. Power Appl., Vol. 143, no. 3, pp. 186--192., 1996.

[12] Y. A. I. Mohamed and T. K. Lee, “Adaptive self-tuning MTPA vector controller for IPMSM drive system,” IEEE Trans. Energy Conver., vol.21, no. 3, pp. 636-644, Sep. 2006.

[13] M. N. Uddin, M. A. Abido, and M. A. Rahman, "Real-time performance evaluation of a genetic-algorithm-based fuzzy logic controller for IPM motor drives," IEEE Trans. Ind. Appl., vol. 41, no. 1, pp. 246-252, Jan./Feb. 2005.
[14] Y. Yang, D. M. Vilathgamuwa, and M. A. Rahman, " Implementation of an articial-neural-network-based real-time adaptive controller for an interior permanent-magnet motor drive," IEEE Trans. Ind. Appl., vol. 39,no. 1, pp. 96-104, Jan./ Feb. 2003.

[15] Marino, R. and Tomei, P., 'Nonlinear Control Design', Prentice Hall, Inc, 1995. 